\title{
Non-human biota assessments for geological disposal facilities - a study of the key uncertainties and importance for dose estimates
}

\author{
A.T.K. Ikonen ${ }^{1}$, K. Smith ${ }^{2}$, C.A. Robinson ${ }^{3}$, I. De La Cruz ${ }^{4}$, T. Lindborg ${ }^{5}$, \\ Y. Thiry ${ }^{6}$, P. Strand ${ }^{7}$ and S. Norris ${ }^{8}$ \\ ${ }^{1}$ Posiva Oy, Olkiluoto, 27160 Eurajoki, Finland \\ 2 Eden Nuclear and Environment, Eden Conference Barn, Low Moor, Penrith, \\ CA10 1XQ, UK \\ ${ }^{3}$ Cove Environmental Consulting Ltd, P.O. Box 13087, Cockburnspath, TD13 9AB, \\ UK \\ ${ }^{4}$ Facilia AB, Gustavslundsvägen 151C, 16751 Bromma, Stockholm, Sweden. \\ 5 SKB, Box 250, SE 10124 Stockholm, Sweden \\ ${ }^{6}$ ANDRA, 1-7, rue Jean-Monnet, F-92298 Châtenay-Malabry, France \\ ${ }^{7}$ NRPA, P.O. Box 55, N-1332 Østerås, Norway \\ ${ }^{8}$ NDA-RWMD, Building 587, Harwell Campus, Didcot, OX11 ORH, UK
}

\begin{abstract}
A programme of work, commissioned within the BIOPROTA collaborative forum, has recently been undertaken to assess the quantitative and qualitative elements of uncertainty associated with nonhuman biota (NHB) dose assessment in relation to the potential long-term release of radionuclides from a geological disposal facility (GDF). This was achieved through combining quantitative sensitivity and qualitative knowledge quality analyses based on the EC ERICA assessment approach and default assessment parameters. The results of the project demonstrate that this combination of approaches may be used to identify important parameters that could be significant in assessments of the impacts of any radionuclide release from a GDF on NHB, and for which there is low confidence. The output is intended to provide information on those parameters that may need to be considered in more detail for site-specific assessments. Such information should help users to enhance the quality of their assessments and build greater confidence in the results.
\end{abstract}

\section{INTRODUCTION}

The assessment of the environmental impacts of planned activities, and the conservation status of protected species and habitats, are required under a range of EC Directives related to, for example, Environmental Impact Assessment, Strategic Environmental Assessment and the protection of habitats. Activities involving the release of radioactive materials to the environment thus often implicitly require an assessment of the exposure of flora and fauna (non-human biota) to ionising radiation. The IAEA Safety Fundamentals also include a principle related to the protection of the environment, which has broader application. The assessment of potential releases from radioactive waste disposal repositories thus require an assessment of impacts arising from long term releases of radionuclides to the biosphere.

Generic assessment methodologies for the assessment of dose to biota exist (e.g. the European Commission-funded ERICA (Environmental Risks from Ionising Radiation: Assessment and Management) approach). However, these have been developed and tested in relationship to current discharges or situations of existing contamination. 
The nature of releases from GDFs poses some interesting problems to the assessment of their potential impacts on the environment [1]. Releases are assumed to occur from deep underground (in the geosphere) at some point in the distant future. At this time, radionuclides may enter the biosphere through the action of groundwater migration. The distribution of radionuclides within the soil column will thus differ from that associated with surface deposition and the time period over which releases are predicted to occur may be thousands of years post-closure. The potential impact of different radionuclides will be determined by the source term, the nature of the geosphere and biosphere into which the release occurs, and the chemical and physical characteristics of the radionuclides concerned.

Assessments of the impact of potential releases from geological repositories are therefore complex and involve the consideration of long time periods and a range of release scenarios.

Environmental assessments, particularly for prospective situations, require the use of models, scenarios, assumptions and extrapolations, all of which involve uncertainties arising from, for example, incomplete parameter information, interactions and imperfect understanding.

A number of organisations have undertaken outline work to assess the environmental impact associated with future releases from deep geological disposal sites for radioactive waste [2]. However, interpretation of these studies and any future assessments are constrained by the availability of, and uncertainty associated with, key assessment parameters.

Approaches for mapping and prioritising the assessment of quantifiable aspects of uncertainty have been developed (such as data spread around a mean value). However, in order to make sensible decisions about addressing uncertainties, it is also important to understand the other sources of uncertainty (such as those arising from model structure, context and parameter value selection) and their significance under different situations. As such, a programme of work was commissioned within the BIOPROTA collaborative forum ${ }^{1}$ to assess the quantitative and qualitative elements of uncertainty associated with non-human biota (NHB) dose assessments in relation to long-term release of radionuclides from GDFs. This has been achieved through quantitative sensitivity and qualitative knowledge quality analyses. These terms may be broadly defined and differentiated as follows:

- Sensitivity analysis is an approach to evaluating the importance of quantitative aspects of uncertainty. It is a "what-if" type of analysis aimed at determining the sensitivity of the outcome to changes in parameters.

- Knowledge quality assessment is an emerging branch of social science, which seeks to address, in a systematic way, the more qualitative aspects of uncertainty, specifically as they relate to the application of models and data to decision-making. It allows the acceptability of a scientific model to be expressed in relation to the application to which it is being applied

- Through these processes, the objective was to identify critical model features and parameters that are both sensitive (i.e. have a large influence on model output) and of low quality (i.e. low knowledge-quality score). This information is intended to enable assessors to ascertain where to focus further effort on determining accurate assessment factors, for example when moving from a generic to a more site-specific assessment.

\section{ASSESSMENT APPROACH}

In order to constrain the scope of the project, the focus of the study was restricted to consideration of the terrestrial and freshwater representative ecosystems, and their constituent components only and a set of radionuclides identified as priorities within the BIOPROTA forum.

\footnotetext{
${ }^{1}$ BIOPROTA is an international forum that was set up to address the key uncertainties in long-term assessments of contaminant releases to the environment arising from radioactive waste disposal. It involves national authorities and agencies with responsibility for achieving safe and acceptable radioactive waste management. Further information is available from www.bioprota.org
} 
The sensitivity analysis and knowledge quality assessment were conducted in parallel with results from both being presented and discussed in context during an international workshop attended by a range of experts in NHB assessment approaches and radioecology assessments for radioactive waste disposal facilities.

\subsection{Sensitivity Analysis}

In order to model and assess the sensitivity of impacts of releases from GDFs, the ERICA assessment approach for NHB [3] was implemented within a sensitivity analysis software programme, EIKOS [4, 5]. EIKOS supports "state of the art" sensitivity analysis methods, which can be used to assess the influence of different model parameters on simulation endpoints. The procedures employed in the current study were Spearman Ranked Correlation Coefficient (SRCC) and the First Order Sensitivity Indices methods.

The study made use of underlying data from the ERICA assessment approach; this approach and the underlying data are described in more detail elsewhere [3]. The analysis was supported by data from other sources where necessary, for example in order to establish distributions of input parameters.

One of the key objectives of the project was to develop an understanding of those aspects of biota dose assessment for geological disposal facilities that would require particular attention in moving from a generic to a site-specific assessment. With this view in mind, the ERICA assessment approach was applied in generic and test-case modes. The generic assessment (based on unit environmental concentrations) was used to identify general issues and pitfalls in the application of the approach to GDF assessments and a baseline understanding of key data gaps/uncertainties. The second stage of the sensitivity analysis was the application of illustrative environmental concentration information for site generic and site-specific scenarios, provided by Posiva [6] and NDA RWMD [7], respectively. For both generic and test cases it was assumed that there was no uncertainty (including variability) in the radionuclide concentrations as the aim of the study as specifically the uncertainties related to the NHB assessment.

\subsection{Knowledge Quality Assessment}

The knowledge base behind an assessment is typically drawn from a range of sources, which may include well-established knowledge, expert judgement, educated guesses and tentative assumptions [8]. In order to evaluate non-quantifiable uncertainties associated with NHB assessments for a GDF, a simplified version of the approach proposed by van der Sluijs [8] was employed whereby expert opinion was elicited on the appropriateness, empirical quality and the theoretical understanding of various aspects of the assessment approach. A questionnaire was developed on the basis of the default assessment data within the ERICA assessment approach, including reference organisms, habitat components, concentration ratios $(\mathrm{CR})$ and distribution coefficients $(\mathrm{Kd})$, radiation weighting factors, and geometry and dosimetry.

The questionnaire was distributed to a range of experts in non-human biota and radioactive waste disposal assessments to elicit their opinion on the quality of the models and data for non-human biota assessment, particularly as they apply to assessments of releases from GDFs. Experts were asked to score assessment data and models on the level of certainty or understanding that can be related to attributes such as theoretical understanding and empirical quality. The views of all experts were collated to determine the degree of consensus around each of the questions posed.

\section{RESULTS}

Results of the sensitivity analysis and knowledge quality assessment are presented below both individually and in combination. More detailed results are presented in [9]. 

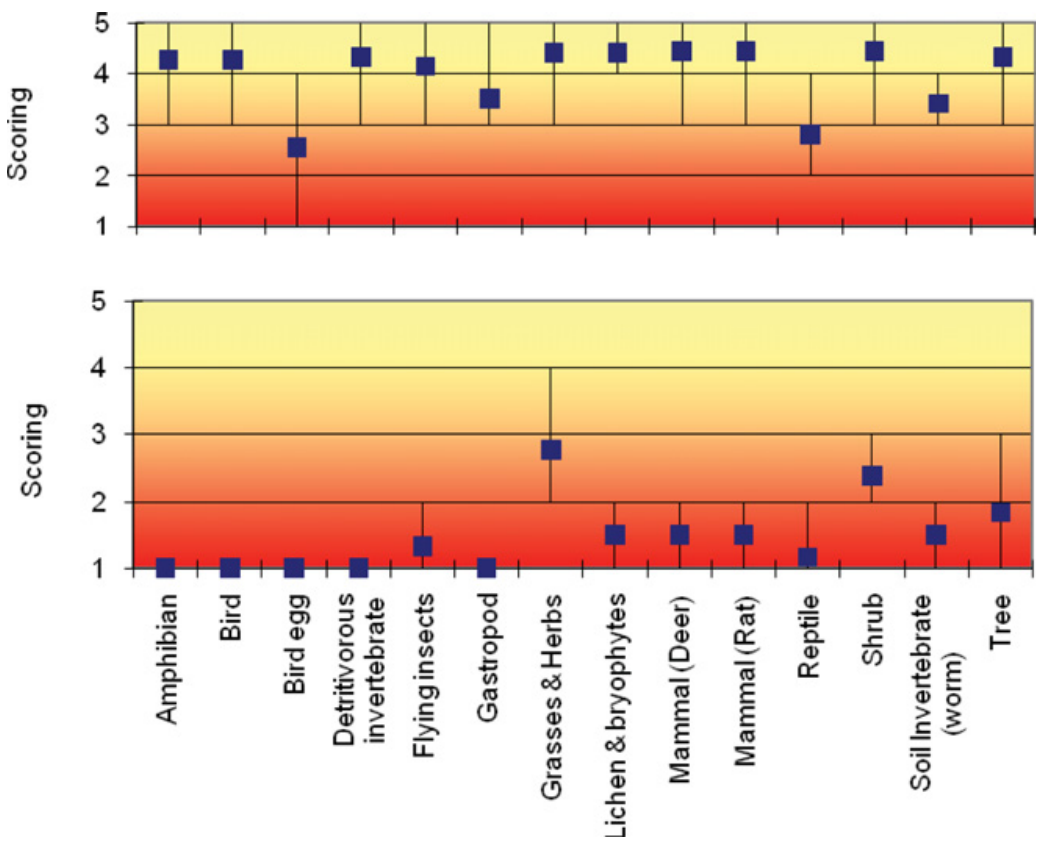

Figure 1. Scoring of empirical quality for CR values in the terrestrial environment for Cs-135 (above) and Np-237 (below). Low numerical scores indicate a low level of confidence in parameter values.

\subsection{Sensitivity Analysis}

Results of the quantitative sensitivity analysis for both generic and test cases indicated that CR is the key input parameter leading to variance in dose rate estimates for all radionuclides. This is to be expected due to the large range in CR (up to 3 orders of magnitude) observed for each radionuclide and reference organism considered.

For the site-specific test cases based on Posiva input data that is predicted for a post-closure release period of 10,000 years in line with Finnish regulations, the key radionuclides were Cl-36 and I-129 in the terrestrial ecosystem and C-14 in the freshwater ecosystem. In addition to $\mathrm{CR}$, Kd was also an important contributor to variation in dose rate for benthic freshwater reference organisms; Kd was not an important parameter affecting dose rates for pelagic organisms.

For the NDA RWMD test case for which a longer post-closure release period is considered, key radionuclides were $\mathrm{Np}-237$, $\mathrm{Po}-210$ and $\mathrm{Ra}-226$. Due to the decay properties of these radionuclides, the weighting factor for alpha radiation also contributes to the variation in dose rate estimates.

For all test cases, low values of unexplained variance were observed, indicating that most of the variance is explained by direct effects of parameters on the dose rate predictions. However, higher values of unexplained variance were observed for alpha-emitting radionuclides, indicating that interactions between parameters contribute to uncertainty; interactions between CR and the weighting factor for alpha radiation would be envisaged for some radionuclides.

\subsection{Knowledge Quality Assessment}

Results of the qualitative knowledge quality assessment indicated that there is a reasonable consensus around the overall ERICA assessment approach although some issues were raised, for example in relation to the appropriateness of the default reference organisms to GDF scenarios - in the terrestrial 


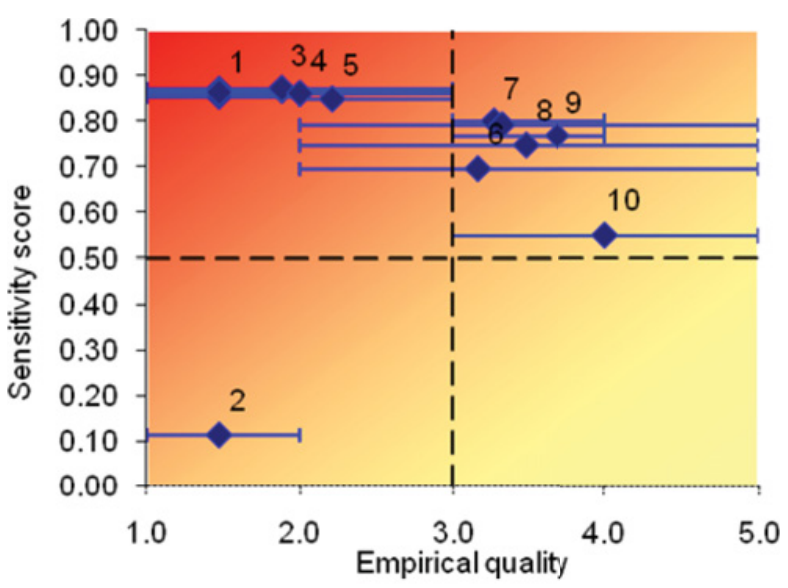

1 Amphibian, Bird, Reptile

2 Bird egg

3 Mammal (Deer \& Rat)

4 Flying insects

5Lichen \& bryophytes

6 Soil Invertebrate (worm)

7 Tree, Gastropod

8 Detritivorous invertebrate

9 Grasses \& Herbs

10 Shrub

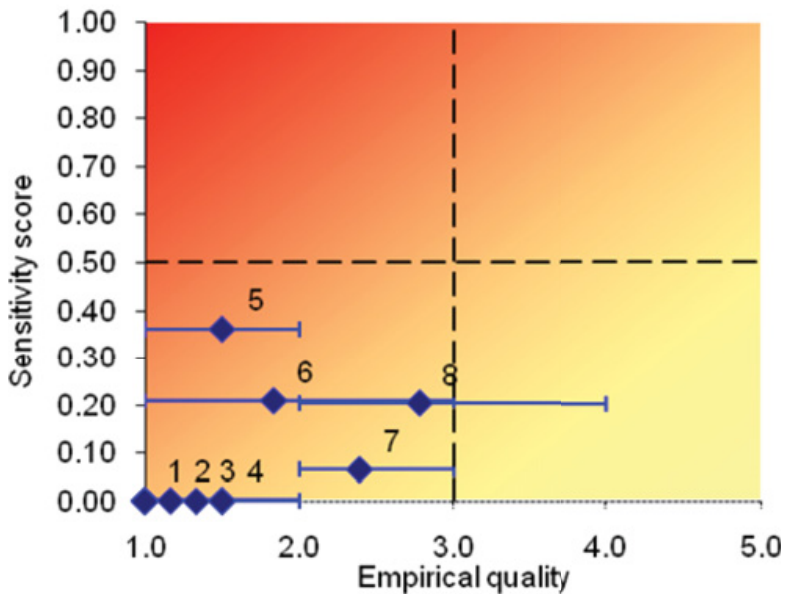

1 Bird, Amphibian, Bird egg, Detritivorous invertebrate, Gastropod

2 Reptile

3 Flying insect

4 Mammal (Deer), Soil invertebrate, Mammal (Rat)

5 Lichen \& bryophyte

6 Tree

7 Shrub

8 Grasses \& Herbs

Figure 2. Uncertainty in $\mathrm{CR}$ for $\mathrm{Cl}-36$ (above) and Po-210 (below) in the terrestrial environment. Parameters that are both sensitive and uncertain appear in the top left hand corner of the figures.

ecosystem it was considered that burrowing animals should be given greater precedence and that the representation of plants could be revised to specifically consider below-ground components, i.e. roots.

Of the assessment parameters considered, CR for C-14, Cl-36, Ni-59, Po-210 and Np-237 in the freshwater ecosystem scored relatively poorly on grounds of empirical quality. For comparison purposes, results of empirical quality scores for Cs-135 and Np-237 CR are presented in Figure 1. Low scores were also assigned to $\mathrm{Kd}$ for $\mathrm{C}-14$ and $\mathrm{Cl}-36$.

\subsection{Identification of key areas of uncertainty}

In the generic sensitivity analysis, concentration ratios for all radionuclides were identified as being responsible for the majority of total dose rate variation and for many of these radionuclides there is a high degree of qualitative uncertainty, particularly for those radionuclides for which empirical data are lacking (e.g. Np-237). However, the practical need to improve confidence in these assessment parameters will depend upon the release scenario being considered.

Therefore, in order to identify the most important parameters in terms of assessment uncertainty, knowledge quality assessment scores were plotted against the quantitative results of the sensitivity analysis for each test case. Results of the sensitivity analysis identified both Cl-36 CR and Po-210 
$\mathrm{CR}$ as important parameters in the terrestrial test cases. However, when results are combined with those from the knowledge quality assessment (Figure 2), the relative importance of the different radionuclides in relation to assessment uncertainty can be identified. In this example, preference should be given to improving Cl-36 concentration ratios over those for Po-210 in order to improve confidence in assessment results, with a particular focus on CR for amphibian, bird, reptile and mammal reference organisms.

\section{CONCLUSIONS}

This assessment has served to demonstrate that a combination of quantitative and qualitative consideration of uncertainties can be used to identify important parameters that could be significant in assessments of the impacts of any radionuclide release from a geological disposal facility on nonhuman biota and for which there is low confidence. The output is intended to identify those parameters that may need to be considered in more detail for site-specific assessments.

The particular conclusions in relation to priority radionuclides and assessment parameters cannot be applied to assessments generally, but serves here to illustrate how the combined quantitative and knowledge quality based consideration of uncertainties can be used to identify important data weaknesses. Application of such an approach to NHB and other assessments for radioactive waste disposal facilities could help enhance the quality of assessments and build greater confidence in the results.

\section{Acknowledgments}

The authors are grateful to Posiva (Finland), SKB (Sweden), ANDRA (France) and NRPA (Norway) for funding this project. Posiva and the UK Nuclear Decommissioning Authority, Radioactive Waste Management Directorate are also gratefully acknowledged for the provision of representative post-closure release data for the purposes of constructing test cases for the sensitivity analysis. The contribution of the following experts to the knowledge quality assessment is also acknowledged: Mike Thorne, Ari Ikonen, Karolina Stark, Graham Smith, Jordi Vives, Adam Kennedy, Gerhard Pröhl, Justin Brown, Karine Beaugelin, Geert Olyslaegers, Deborah Oughton, Pål Andersson and Nick Beresford.

\section{References}

[1] Robinson C.A., Smith K. and Norris S., J. Rad. Protection 30 (2010) 161-174.

[2] BIOPROTA, International Forum on the Application of Guidance and Methodologies for Assessing Radiation Impacts on Non-Human Biota from Radioactive Waste Disposal Facilities, Lappeenranta, Finland, 31 January - 1 February 2007, www.bioprota.org.

[3] ERICA, D-ERICA: (N. Beresford, J. Brown, D. Copplestone, J. Garnier-Laplace, B. Howard, C.-M. Larsson, D. Oughton, G. Pröhl and I. Zinger Eds.). www.ceh.ac.uk/protect/ ERICAdeliverables.html.

[4] Ekström P.-A., (2005). Eikos Available from http://ecolego.facilia.se/ecolego/files/eikos_help. pdf.

[5] Ekström P,-A. and Broed R., 2006 Posiva Working Report 2006-31.

[6] Broed, R., Avila, R., Bergström, U., Hjerpe, T. and Ikonen, A.T.K., Posiva Working Report $2007-$ 109. Posiva Oy, Eurajoki, Finland, 2007, www.posiva.fi.

[7] Nirex, Technical Note No. 499169, (Nirex, UK, 2001).

[8] van der Sluijs J., Water Sci. Technol. 52 (2005) 87-92.

[9] Smith K., Robinson C.A., Jackson D., de la Cruz I., Zinger I. and Avila R., Posiva Working report 2010-69, (2010) www.posiva.fi. 